\title{
Effects of menthone and piperitone on growth, chlorophyll a and $\beta$-carotene production in Dunaliella salina
}

\author{
Mina Zarei ${ }^{1,2,5}$, Mohammad Ali Mobasher ${ }^{3,4}$, Mohammad Hossein Morowvat ${ }^{1}$, Pegah Mousavi ${ }^{2,6}$, Nima Montazeri- \\ Najafabady $^{2}$, Nasim Hajighahramani ${ }^{2}$, Younes Ghasemi ${ }^{1,2,6^{*}}$ \\ ${ }^{1}$ Pharmaceutical Sciences Research Center, School of Pharmacy, Shiraz University of Medical Sciences, P.O. Box 71345-1583, Shiraz, Iran. ${ }^{2}$ Department of \\ Pharmaceutical Biotechnology, School of Pharmacy, Shiraz University of Medical Sciences, P.O. Box 71468-64685, Shiraz, Iran. ${ }^{3}$ Department of Medical \\ Biotechnology, School of Medicine, Fasa University of Medical Sciences, Fasa, Fars, Iran. ${ }^{4}$ Noncommunicable Diseases Research Center, School of \\ Medicine, Fasa University of Medical Sciences, Fasa, Iran. ${ }^{5}$ Islamic Azad University, Jahrom Branch, Jahrom, Fars, Iran. ${ }^{6}$ Department of Medical \\ Biotechnology, School of Advanced Medical Sciences and Technologies, Shiraz University of Medical Sciences, Shiraz, Iran.
}

\section{ARTICLE INFO}

Article history:

Received on: 21/05/2016

Revised on: 14/06/2016

Accepted on: 12/07/2016

Available online: 26/09/2016

Key words:

Dunaliella salina,

monoterpenes, menthone,

piperitone, chlorophyll a, $\beta$ -

\begin{abstract}
Recently, studying essential oils and secondary metabolites of plants and microalgae have received much attention. The biosynthesis of the secondary metabolites is strongly influenced by different environmental factors. Monoterpenes as a main fraction of essential oils of fruits and vegetables have many clinical applications. They could inhibit the carcinogenesis processes and therefore might be effective in treatment of cancers. Dunaliella salina, a photosynthetic green microalga is known as a rich source for $\beta$-carotene production. In this study, the effects of some monoterpenes including menthone and piperitone was investigated on yield of production of $\beta$-carotene were studied. Menthone and piperitone as parameters of stress can make tensions to the medium of $D$. salina increasing its $\beta$-carotene and chlorophyll $a$ content in every single cell but on the other hand these two monoterpenes cause a decrease in the concentration of $\beta$-carotene and chlorophyll $a$.
\end{abstract}

\section{INTRODUCTION}

Essential oils helps the plants to easly preserve and adapt to the environmental stress conditions (Errafiy et al., 2013, Figueiredo et al., 2008). Monoterpenes are biosynthesised secondary metabolites that obtained from plants and microalgae. They are subgroup of terpenoids with anti-protozoan, antimicrobial, disinfectant, antiseptic, wound healing, antiparasitic and anti-cancer properties (Bakkali et al., 2008; Dorman et al., 2000; Ghasemi et al., 2007a; Leal et al., 2013). They are widely used in food industry, clinical practices, cosmetics and agriculture (Burt, 2004, Edris, 2007). In fact, monoterpenes are hydrocarbons resulting from condensation of two isoprene units.

\footnotetext{
* Corresponding Author

Younes Ghasemi, Pharmaceutical Sciences Research Center, School of Pharmacy, Shiraz University of Medical Sciences, P.O. Box 71345-1583, Shiraz, Iran. Email: ghasemiy @ sums.ac.ir
}

They are well distributed in plant and vegetable essential oils (Knudsen et al., 2006). Menthone and piperitone are the main fractions of Menthapiperita essence with anti-microbial properties and are widely used in fragrance and pharmaceutical industries (Iscan et al., 2002; Kalemba and Kunicka, 2003). Microalgae are microorganisms of multi purposes, with a variety of potential applications in food, environmental biotechnology, chemical convertors and biofuel (Ghasemi et al., 2007b; Ghasemi et al., 2011a; Ghasemi et al., 2008a; Ghasemi et al., 2012; Shaker et al., 2015; Yazdi et al., 2005). Dunaliella salina, is a photosynthetic unicellular green microalga that lacks a rigid wall (Borowitzka, 2013). Among different species of microorganisms, D. salina has the most potential for production of $\beta$-carotene which can accumulate $\beta$-carotene up to about $13.8 \%$ of its total dry cell weight (Ye et al., 2008). The global market of natural pigments has a high demand for carotenoids because of its wide use in coloring agents, medicine, cosmetics and food industries. 
Hence, different biochemical genetic and bioprocess experiments could be suggested to maximize the total carotenoid production in this microalga (Courchesne et al., 2009). In this study, the effects of these two monoterpenes on chlorophyll and $\beta$-carotene production in $D$. salina were evaluated.

\section{MATERIALS AND METHODS}

\section{Strain and culture conditions}

The microalgae D. salina was isolated from Maharlu Salt Lake, 27 kilometers southeast of Shiraz, Iran. Identification was done through morphological and taxonomical descriptions(Preisig, 1992). Besides, PCR reaction of $18 \mathrm{~S}$ rRNA with universal primers were carried out and products were evaluated by $1 \%$ agarose gel electrophoresis(Ghasemi et al., 2011b, Ghasemi et al., 2008b).The single colony of D.salina was inoculated in modified Johnson broth containing $12 \% \mathrm{NaCl}, \quad 1.5 \mathrm{~g} \quad \mathrm{MgCl}_{2} .6 \mathrm{H}_{2} \mathrm{O}, \quad 0.5 \mathrm{~g}$ $\mathrm{MgSO} 4.7 \mathrm{H} 2 \mathrm{O}, 0.2 \mathrm{~g} \mathrm{KCl}, 0.2 \mathrm{~g} \mathrm{CaCl}_{2} .2 \mathrm{H}_{2} \mathrm{O}, 1 \mathrm{~g} \mathrm{KNO}{ }_{3}, 0.043 \mathrm{~g}$ $\mathrm{NaHCO}_{3}, 0.035 \mathrm{~g} \mathrm{KH}_{2} \mathrm{PO}_{4}$, by addition of distilled water to a total volume of 1 liter ( $\mathrm{pH}$ adjusted to 7.5 by $\mathrm{HCl}$ ). Microalgae growth was monitored under condition $37 \mu \mathrm{mol} \mathrm{m} \mathrm{m}^{-2}$ illumination and unlimited aerated condition during 35 days for D. salina. Temperature was adjusted at $25 \pm 2{ }^{\circ} \mathrm{C}$. Cell number and optical density was measured by using anoptical microscope and UV/Visible spectrophotometer (U-0080D-Tokyo, Japan) at 620 $\mathrm{nm}$ respectively. For cell count, each time $20 \mu \mathrm{L}$ of microalgae suspension was removed through sampling tube and then direct count was performed using Neubauer hemocytometer and a light microscope (TCM400-Labomed, CA, USA).

\section{Essential oils treatment}

Piperitone and menthone were added to $100 \mathrm{~mL}$ culture medium in concentrations of $0,1,1.5,2,2.5 \mu \mathrm{L} / \mathrm{mL}$. concentrations over the range of $2.5 \mu \mathrm{L} / \mathrm{mL}$ caused at least the cell count in the defined medium. Erlenmeyers were incubated at $22^{\circ} \mathrm{C}$ in a room with light tension of $5000 \mathrm{~lx}$. After treatment of cultures with piperitone and menthone, cell counting was done using Neubauer haemocytometer every 4 days.

\section{Analytical procedure}

For evaluation of the produced chlorophyll $a, 3 \mathrm{~mL}$ of microalgae culture was centrifuged at $2500 \mathrm{rpm}$, for $10 \mathrm{~min}$. The supernatant was replaced with $80 \%$ acetone solution and the suspension was shaked well by vortex, then after centrifugation (2500 rpm, $10 \mathrm{~min}$ ), absorbance of the supernatant solutions in 668.2 and $664.8 \mathrm{~nm}$ were measured by using a spectrophotometer. According to Eijckelhoff and Dekker calculations, the amount of chlorophyll $a$ was achieved (Eq. 1):

Eq. 1: $\quad$ Chl. a $(\mu \mathrm{g} / \mathrm{mL})=12.25_{\mathrm{A} 668.2}-2.79_{\mathrm{A} 664.8}$

All experiments were done in triplicate with three time observations. For evaluation of produced $\beta$-carotene, $1 \mathrm{~mL}$ of microalgal culture was centrifuged in $3000 \mathrm{rpm}$ for $10 \mathrm{~min}$, and then the supernatant was replaced with $3 \mathrm{~mL}$ hexane/ethanol solution with the fraction of $1 / 2$. After vortex the solution was centrifuged (3000 rpm, $10 \mathrm{~min}$ ) and supernatant was separated into two isolated phases. The upper phase was hexane phase including $\beta$-carotene compounds. According to equation below (Eq. 2), the amount of $\beta$-carotene was calculated in $\mu \mathrm{g} / \mathrm{mL}$ :

$$
\text { Eq. 2: } \quad \beta \text {-carotene }(\mu \mathrm{g} / \mathrm{ml})=25.2 \times \mathrm{A}_{450}
$$

\section{Phylogenic analysis of the isolated strain}

The gene sequence of our isolated $D$. salina was compared with other gene sequences in NCBI library by blast software. It was achieved a homology of $99 \%$ with the other Dunaliella strains. The phylogenic tree was drawn by the help of MEGA4 software according to neighbor joining method. According to phylogenic tree, D.salina has the most similarity to D. bardawil (Fig. 1).

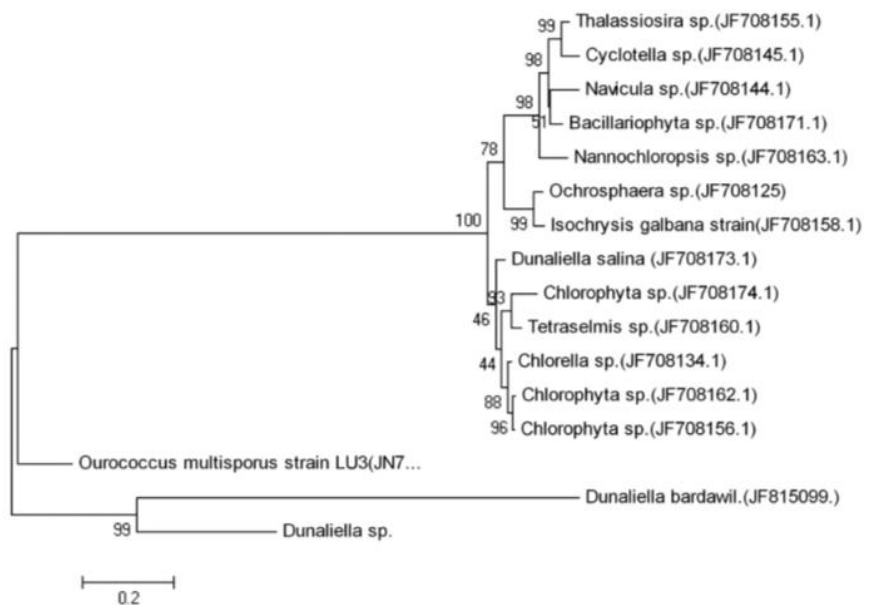

Fig. 1: Molecular phylogenetic analysis of the isolated $D$. salina strain with some related microalgal strains according to $18 \mathrm{~S}$ rRNA gene. The evolution history was inferred by using the neighbor joining method. The bootstrap consensus tree inferred from 500 replicates. Branches corresponding to partitions reproduced in less than $50 \%$ bootstrap replicates are collapsed. The analysis involved 16 nucleotide sequences (accession numbers in parenthesis). All positions containing gaps and missing data were eliminated. Evolutionary analysis was conducted in MEGA4.

\section{Statistical analysis}

For the statistical analysis, identification of significant differences between the treatment groups was analyzed using ANOVA and the $t$-test. The chosen level of significance for all statistical tests was $p<0.05$ Statistical computation was performed using the IBM SPSS16.0 software (SPSS Inc., Chicago, IL, USA).

\section{RESULTS AND DISCUSSION}

The isolated microalgal strain found to be a $D$. salina strain. The results of phylogenetic studies are shown in Fig. 1. Growth curve of $D$. salina during 16 days after culture in Johnson medium was depicted in Fig. 2. As it has been shown, increasing the concentration of piperitone monoterpene from 0 to $2.5 \mu \mathrm{g} / \mathrm{mL}$, will decrease the number of cells significantly. In high levels $(>2.5$ 
$\mu \mathrm{g} / \mathrm{mL}$ ), piperitone had extensive negative effect on growth and viability of $D$. salina cells. Even after treatment with $2.5 \mu \mathrm{g} / \mathrm{mL}$ of piperitone, between 12 and 16 days, the cell count was reduced from 192000 to 73000 cells/mL (Fig. 2).

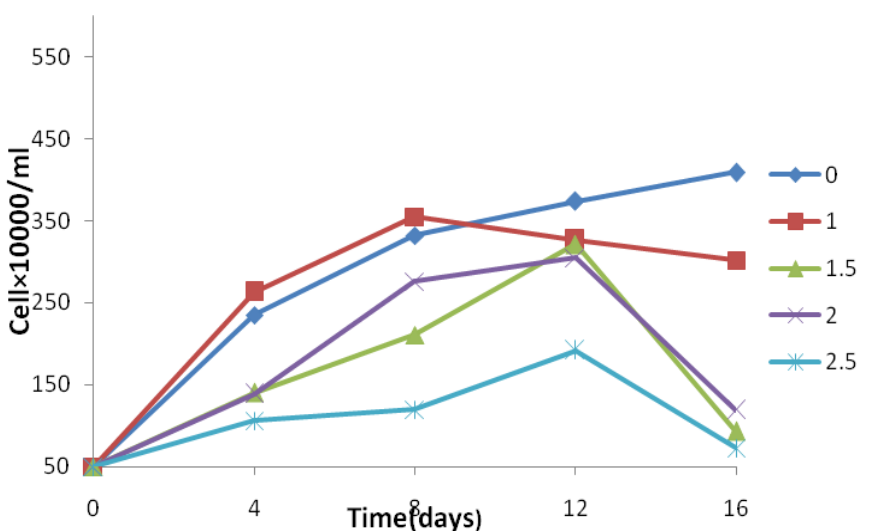

Fig. 2: Effects of different concentrations of piperitone on growth of $D$. salina during 16 days of experiment.

Overall, by increasing the concentration of menthone, the growth curve of $D$. salina showed a descending pathway. But the slope was gentler than piperitone. After treatment with high concentration of menthone $(\geq 2.5 \mu \mathrm{g} / \mathrm{mL})$, during the last four days, the cell count was reduced from 113000 to 92000 cell $/ \mathrm{mL}$ (Fig. 3).

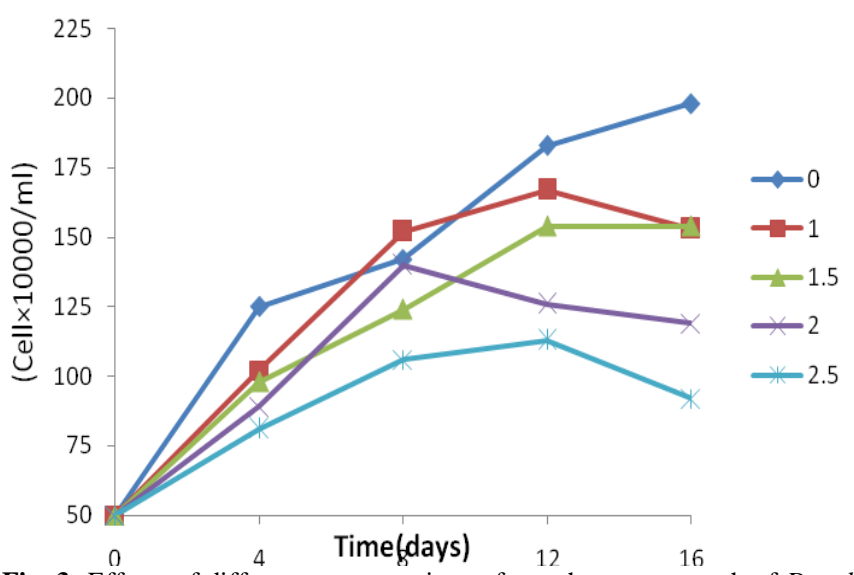

Fig. 3: Effects of different concentrations of menthone on growth of $D$. salina during 16 days of experiment.

By increasing the concentration of menthone from 0 to $2.5 \mu \mathrm{g} / \mathrm{mL}$, the concentration/volume of chlorophyll $a$ was decreased severely (Table 1). The most chlorophyll content was belonging to control group (without monoterpene) and the less chlorophyll $a$ was for the highest concentration $(2.5 \mu \mathrm{g} / \mathrm{mL})$. After 16 days of incubation, the control group compared with the sample group, chlorophyll content in all groups was increased in every single cell, but the total content of chlorophyll was lower than the control group (Table 1).

The result of additional piperitone on chlorophyll $a$ was as same as menthone. By additional concentration of menthone from 0 to $2.5 \mu \mathrm{g} / \mathrm{mL}$, the concentration of chlorophyll/volume was decreased severally (Table 2).Generally, by increasing the concentration of menthone from 0 to $2.5 \mu \mathrm{g} / \mathrm{mL}, \beta$-carotene production was increased and the total contents of $\beta$-carotene per volume was going decreased but the $\beta$-carotene contents in every cell was going increased (Table 3). But when the concentration of menthone was up to $2.5 \mu \mathrm{g} / \mathrm{mL}, \beta$-carotene production was reduced (Table 3 ) with an inverse relationship.

Table 1: Effects of menthone on chlorophyll a concentration in D. salina during 16 days of experiment.

\begin{tabular}{ccccc}
\hline $\begin{array}{c}\text { Menthone } \\
\text { concentration } \\
(\boldsymbol{\mu L} / \mathbf{m L})\end{array}$ & $\mathbf{4}^{\text {th }} \mathbf{d a y}$ & $\mathbf{8}^{\text {th }}$ day & $\mathbf{1 2}^{\text {th }} \mathbf{d a y}$ & $\mathbf{1 6}^{\text {th }}$ day \\
\hline 0 & $1.177 \pm .09$ & $2.016 \pm .01$ & $4.508 \pm .05$ & $6.729 \pm .11$ \\
1 & $1.155 \pm .09$ & $1.701 \pm .06$ & $4.327 \pm .07$ & $6.516 \pm .16$ \\
1.5 & $1.086 \pm .43$ & $1.597 \pm .08$ & $3.844 \pm .019$ & $6.522 \pm .11$ \\
2 & 0.688 .06 & $1.597 \pm .05$ & $3.427 \pm .07$ & $6.398 \pm .15$ \\
2.5 & $0.508 \pm .04$ & $1.301 \pm .11$ & $2.623 \pm .09$ & $5.432 \pm .39$ \\
\hline
\end{tabular}

Table 2: Effects of piperitone on chlorophyll a concentration in D. salina during 16 days of experiment.

\begin{tabular}{ccccc}
\hline $\begin{array}{c}\text { Piperitone } \\
\text { concentration } \\
(\boldsymbol{\mu L} / \mathbf{m L})\end{array}$ & $\mathbf{4}^{\text {th }} \mathbf{d a y}$ & $\mathbf{8}^{\text {th }}$ day & $\mathbf{1 2}^{\text {th }} \mathbf{d a y}$ & $\mathbf{1 6}^{\text {th }}$ day \\
\hline 0 & $0.978 \pm .09$ & $2.595 \pm .04$ & $4.096 \pm .06$ & $5.419 \pm .06$ \\
1 & $0.976 \pm .08$ & $2.343 \pm .05$ & $3.389 \pm .07$ & $5.271 \pm .10$ \\
1.5 & $1.052 \pm-06$ & $2.738 \pm .07$ & $3.369 \pm .04$ & $5.071 \pm .08$ \\
2 & $0.943 \pm .08$ & $2.727 \pm .03$ & $3.635 \pm .06$ & $4.951 \pm .01$ \\
2.5 & $0.860 \pm .06$ & $1.995 \pm .04$ & $3.176 \pm .07$ & $4.661 \pm .06$ \\
\hline
\end{tabular}

Table 3: Effects of menthone on $\beta$-carotene production in D. salina during 16 days of experiment.

\begin{tabular}{ccccc}
\hline $\begin{array}{c}\text { Menthone } \\
\text { concentrations } \\
(\boldsymbol{\mu L} / \mathbf{m L})\end{array}$ & $\mathbf{4}^{\text {th }}$ day & $\mathbf{8}^{\text {th }}$ day & $\mathbf{1 2}^{\text {th }}$ day & $\mathbf{1 6}^{\text {th }}$ day \\
\hline 0 & 0.5796 & 1.3188 & 3.4272 & 5.163 \\
1 & 0.7896 & 1.3608 & 3.3459 & 4.3428 \\
1.5 & 0.7056 & 1.4952 & 3.2467 & 4.8468 \\
2 & 0.84 & 1.7388 & 2.94 & 3.654 \\
2.5 & 0.4956 & 0.9996 & 2.4537 & 3.457 \\
\hline
\end{tabular}

Despite increased levels of $\beta$-carotene after treatment with piperitone $(\geq 2.5 \mu \mathrm{g} / \mathrm{mL})$, there was a decrease in total content of $\beta$-carotene in control group (5.41 to $4.66 \mu \mathrm{g} / \mathrm{mL}$ ).

The human cells are exposed to a wide range of oxidants in air, foods and surroundings (Brunekreef and Holgate, 2002, Valko et al., 2005). These oxidants can harm proteins and nucleotides within the cells through free radicals. A surplus of plant reactions exist to find a way around the potentially harmful effects caused by salinity light, drought, pathogen infections, extreme temperatures, and other stresses. In 1940s, potency of phenolic compounds in prohibition of fatty acid oxidation was understood (Ghio et al., 2012). Since then the usage of synthetic antioxidants has been developed but nowadays their application is reduced due to their disadvantages on human health (Kmiecik et al., 2011). $\beta$-carotene as a natural and safe anti-oxidant is a good alternative.

Nowadays obtaining new methods for production of large amounts of $\beta$-carotene is very important. Application of stressful situations in culture conditions of $D$. salina increase the 
amounts of $\beta$-carotene in cell contents. Addition of monoterpenes like piperitone and menthone through induction of stress can increase $\beta$-carotene contents of the cells (Yan et al., 2011). Piperitone and menthone by prohibiting effect on growth of $D$. salina caused a reduction in cell counts, so the amounts of $\beta$ carotene in a defined volume was decreased but the $\beta$-carotene contents in each cell was increased. Considering the effects of monoterpenes menthone and piperitone on the pattern of $D$. salina growth curve it was revealed that piperitone had negative effects on microalgal cell growth. Monoterpenes could interrupt the microtubules dynamicity by joining to tubulin heterodimers. So the cell cycle will be arrested in $\mathrm{G}_{0} / \mathrm{G}_{1}$ phase (Choudhury et al., 2010). Stressful conditions induced by different concentrations of monoterpenes piperitone and menthone (from 0.5 to $2.5 \mu \mathrm{g} / \mathrm{mL}$ ) had a positive effect on chlorophyll $a$ content in every single microalgal cell but by considering the descending pattern of cell growth curves, the amount of chlorophyll/volume was reduced.

Foyer et al. showed that increasing of photosynthesis and accumulation of chlorophyll in chloroplasts are coping strategies to combat with stress and ROS effects in microalgae and plants (Foyer and Shigeoka, 2011). Munne-Bosch investigated the role of a-tocopherol in plant stress tolerance (Munne-Bosch, 2005). His study indicated that the amount of a-tocopherol levels in a variety of environmental constraints change differentially and depending on the vastness of the stress and species sensitivity to stress. Khorasaninejad et al. have studied the effect of salinity stress on growth parameter essential oil yield and constituent of peppermint (Khorasaninejad et al., 2010). The results showed that by attendance of high salinity in surrounding the ability of plants to survive was in pathway relationship.

Carotenoids and chlorophyllshave major roles to overcome with oxidative damages in living organisms (Roginsky and Lissi, 2005). $\beta$-carotene and chlorophyll are among the most important antioxidants in the living organisms. Stressful situations can increase the yield of their production as a prophylactic mechanism to overcome destructive effects of ROS and free radicals (Kara et al., 2013). Monoterpenes piperitone and menthone can increase the production of $\beta$-carotene and chlorophyll by induction of stress to the microalgae cells, which could be useful to improve the carotenoid production.

In this study we showed that menthone and piperitone as parameters of stress can make tensions to the medium of $D$. salina, increasing its $\beta$-carotene and chlorophyll content in every single cell. On the other hand, these two monoterpenes cause a decrease in the concentration of $\beta$-carotene and chlorophyll. To increase the amount of chlorophyll and $\beta$-carotene in D. salina in the worth environmental condition, it is a special prominence for microalgae for more attention to exploit for food, industries and medical applications.

Financial support and sponsorship: This study was financially supported by Research Deputy of Shiraz University of Medical Sciences, Shiraz, Iran.

Conflict of Interests: There are no conflicts of interest.

\section{REFERENCES}

Bakkali F, Averbeck S, Averbeck D, Idaomar M. Biological effects of essential oils - A review. Food Chem. Toxicol., 2008; 46(2): 446-75.

Borowitzka MA. 2013. Dunaliella: Biology, production, and markets. In: Richmond A, Hu Q, editors. Handbook of microalgal culture: Applied phycology and biotechnology. Second ed. Oxford, UK: John Wiley and Sons. p. 359-68.

Brunekreef B, Holgate ST. Air pollution and health. Lancet., 2002; 360(9341):1233-42.

Burt S. Essential oils: Their antibacterial properties and potential applications in foods-A review. Int. J. Food Microbiol., 2004; 94(3): 223-53.

Choudhury D, Das A, Bhattacharya A, Chakrabarti G. Aqueous extract of ginger shows antiproliferative activity through disruption of microtubule network of cancer cells. Food Chem. Toxicol., 2010; 48(10):2872-80

Courchesne NMD, Parisien A, Wang B, Lan CQ. Enhancement of lipid production using biochemical, genetic and transcription factor engineering approaches. J. Biotechnol., 2009;141(1-2):31-41.

Dorman HJD, Surai P, Deans SG. In vitro antioxidant activity of a number of plant essential oils and phytoconstituents. J. Essent. Oil Res., 2000;12(2):241-8.

Edris AE. Pharmaceutical and therapeutic potentials of essential oils and their individual volatile constituents: A review. Phytother. Res., 2007;21(4):308-23.

Errafiy N, Ammar E, Soukri A. Protective effect of some essential oils against oxidative and nitrosative stress on Tetrahymena thermophila growth. J. Essent. Oil Res., 2013;25(4):339-47.

Figueiredo AC, Barroso JG, Pedro LG, Scheffer JJC. Factors affecting secondary metabolite production in plants: Volatile components and essential oils. Flavour Fragrance J., 2008;23(4):213-26.

Foyer $\mathrm{CH}$, Shigeoka S. Understanding oxidative stress and antioxidant functions to enhance photosynthesis. Plant Physiol. 2011;155(1):93-100.

Ghasemi Y, Khalaj A, Mohagheghzadeh A, Khosravi AR, Morowvat MH. Composition and antimicrobial activity of the essential oil and extract of Hypericum elongatum. J. Appl. Sci., 2007a;7(18):2671-5.

Ghasemi Y, Faramarzi MA, Arjmand-Inalou M, Mohagheghzadeh A, Shokravi S, Morowvat MH. Side-chain cleavage and C-20 ketone reduction of hydrocortisone by a natural isolate of Chroococcus dispersus. Ann. Microbiol., 2007b;57(4):577-81.

Ghasemi Y, Rasoul-Amini S, Morowvat MH, Azam SBM, Shokravi S, Mohagheghzadeh A, et al. Bioconversion of hydrocortisone by unicellular microalga Oocystis pusilla. Biotechnology., 2008a;7(2):293-8.

Ghasemi Y, Rasoul-Amini S, Morowvat MH, Raee MJ, Ghoshoon MB, Nouri F, et al. Characterization of hydrocortisone biometabolites and $18 \mathrm{~S}$ rRNA gene in Chlamydomonas reinhardtii cultures. Molecules., 2008b;13(10):2416-25.

Ghasemi Y, Rasoul-Amini S, Morowvat MH. Algae for the production of SCP. Bioprocess Sciences and Technology: Nova Science Publishers, Inc.; 2011a. p. 163-84.

Ghasemi Y, Rasoul-Amini S, Kazemi A, Zarrinic G, Morowvat MH, Kargar M. Isolation and characterization of some moderately halophilic bacteria with lipase activity. Mikrobiologiia., 2011b;80(4):47781 .

Ghasemi Y, Rasoul-Amini S, Naseri AT, Montazeri-Najafabady N, Mobasher MA, Dabbagh F. Microalgae biofuel potentials (Review) Appl. Biochem. Microbiol., 2012;48(2):126-44.

Ghio AJ, Carraway MS, Madden MC. Composition of air pollution particles and oxidative stress in cells, tissues, and living systems. J. Toxicol. Environ. Health B., 2012;15(1):1-21.

Iscan G, Kirimer N, Kürkcüoglu Mn, Baser HC, Demirci F. Antimicrobial screening of Mentha piperita essential oils. J. Agric. Food Chem., 2002;50(14):3943-6.

Kalemba D, Kunicka A. Antibacterial and antifungal properties of essential oils. Curr. Med. Chem., 2003;10(10):813-29. 
Kara A, Akman S, Ozkanlar S, Tozoglu U, Kalkan Y, Canakci $\mathrm{CF}$, et al. Immune modulatory and antioxidant effects of melatonin in experimental periodontitis in rats. Free Radic. Biol. Med., 2013;55:21-6.

Khorasaninejad S, Mousavi A, Soltanloo H, Hemmati K, Khalighi A. The effect of salinity stress on growth parameters, essential oil yield and constituent of peppermint (Mentha piperita L.). World Appl. Sci. J., 2010;11(11):1403-7.

Kmiecik D, Korczak J, Rudzińska M, Kobus-Cisowska J, Gramza-Michałowska A, Hęś M. $\beta$-Sitosterol and campesterol stabilisation by natural and synthetic antioxidants during heating. Food Chem., 2011; 128(4):937-42.

Knudsen JT, Eriksson R, Gershenzon J, Ståhl B. Diversity and distribution of floral scent. Bot. Rev., 2006; 72(1): 1-120.

Leal SM, Pino N, Stashenko EE, Martínez JR, Escobar P. Antiprotozoal activity of essential oils derived from Piper spp. grown in Colombia. J. Essent. Oil Res., 2013; 25(6):512-9.

Munne-Bosch S. The role of $\alpha$-tocopherol in plant stress tolerance. J. Plant Physiol., 2005; 162(7): 743-8. 1992. $1-15 \mathrm{p}$

Preisig HR. Morphology and taxonomy: CRC, Boca Raton;

Roginsky V, Lissi EA. Review of methods to determine chainbreaking antioxidant activity in food. Food Chem., 2005; 92(2): 235-54.

Shaker S, Nemati A, Montazeri-Najafabady N, Mobasher MA, Morowvat MH, Ghasemi Y. Treating urban wastewater: Nutrient removal by using immobilized green algae in batch cultures. Int. J. Phytorem., 2015;17(12):1177-82.
Valko M, Morris H, Cronin MTD. Metals, toxicity and oxidative stress. Curr. Med. Chem., 2005; 12(10): 1161-208.

Yan G-l, Liang H-y, Wang Z-q, Yang X-f, Liu D, Liu J-f, et al. Important role of catalase in the production of $\beta$-carotene by recombinant Saccharomyces cerevisiae under $\mathrm{H}_{2} \mathrm{O}_{2}$ stress. Curr. Microbiol., 2011;62(3):1056-61.

Yazdi MT, Ghasemi Y, Ghasemian A, Shokravi S, Niknahad H, Amini $\mathrm{M}$, et al. Bioconversion of hydrocortisone by cyanobacterium Fischerella ambigua PTCC 1635. World J. Microbiol. Biotechnol., 2005;21(6-7):811-4

Ye Z-W, Jiang J-G, Wu G-H. Biosynthesis and regulation of carotenoids in Dunaliella: Progresses and prospects. Biotechnol. Adv., 2008;26(4):352-60.

\section{How to cite this article:}

Zarei M, Mobasher MA, Morowvat MH, Mousavi P, MontazeriNajafabady N, Hajighahramani N, Ghasemi Y. Effects of menthone and piperitone on growth, chlorophyll a and $\beta$-carotene production in Dunaliella salina. J App Pharm Sci, 2016; 6 (09): 215-219. 